\title{
The Role of Oxidized Cholesterol in Diabetes-Induced Lysosomal Dysfunction in the Brain
}

\author{
Catrina Sims-Robinson ${ }^{1,2,3}$ - Anna Bakeman ${ }^{1}$ - Andrew Rosko ${ }^{1}$. \\ Rebecca Glasser $^{1}$ • Eva L. Feldman ${ }^{1}$
}

Received: 11 November 2014 / Accepted: 3 May 2015 /Published online: 15 May 2015

(C) The Author(s) 2015. This article is published with open access at Springerlink.com

\begin{abstract}
Abnormalities in lysosomal function have been reported in diabetes, aging, and age-related degenerative diseases. These lysosomal abnormalities are an early manifestation of neurodegenerative diseases and often precede the onset of clinical symptoms such as learning and memory deficits; however, the mechanism underlying lysosomal dysfunction is not known. In the current study, we investigated the mechanism underlying lysosomal dysfunction in the cortex and hippocampi, key structures involved in learning and memory, of a type 2 diabetes (T2D) mouse model, the leptin receptor deficient $\mathrm{db} / \mathrm{db}$ mouse. We demonstrate for the first time that diabetes leads to destabilization of lysosomes as well as alterations in the protein expression, activity, and/or trafficking of two lysosomal enzymes, hexosaminidase A and cathepsin D, in the hippocampus of $\mathrm{db} / \mathrm{db}$ mice. Pioglitazone, a thiazolidinedione (TZD) commonly used in the treatment of diabetes due to its ability to improve insulin sensitivity and reverse hyperglycemia, was ineffective in reversing the diabetes-induced changes on lysosomal enzymes. Our previous work revealed that pioglitazone does not reverse hypercholesterolemia; thus, we investigated whether cholesterol plays a role in diabetes-induced lysosomal changes. In vitro, cholesterol promoted the destabilization of lysosomes,
\end{abstract}

Catrina Sims-Robinson

robinsoc@musc.edu

1 Department of Neurology, University of Michigan, Ann Arbor, MI 48109, USA

2 Department of Neurosciences, Medical University of South Carolina, Charleston, SC 29425, USA

3 Department of Neurology and Neurosurgery, Medical University of South Carolina, 96 Jonathan Lucas Street, 309D2 Clinical Sciences Building, MSC 606, Charleston, SC 29425, USA suggesting that lysosomal-related changes associated with diabetes are due to elevated levels of cholesterol. Since lysosome dysfunction precedes neurodegeneration, cognitive deficits, and Alzheimer's disease neuropathology, our results may provide a potential mechanism that links diabetes with complications of the central nervous system.

Keywords Type 2 diabetes · Brain · Lysosome · Cathepsin D · Cholesterol · Central nervous system

\section{Introduction}

Diabetes mellitus, which currently affects 25.8 million Americans, is a complex metabolic disorder characterized by hyperglycemia. Type 2 diabetes (T2D) accounts for approximately 90-95\% of all diabetes cases and is associated with obesity and hyperinsulinemia. Various complications are associated with diabetes, including retinopathy, nephropathy, neuropathy, and cardiovascular disease [1], and the impact of diabetes on the central nervous system is gaining attention. It is also believed by some that diabetes accelerates brain aging [2, 3]. Aging and age-related diseases may involve abnormalities in the endosomal-lysosomal system, which is an early manifestation of neurodegeneration [4]. Furthermore, lysosomal dysfunction contributes to the accumulation of protein aggregates, a common occurrence in neurodegenerative disorders $[5,6]$.

Lysosomes are involved in numerous functions, including cell death, exocytosis, endocytosis/phagocytosis, and autophagy. Many of these functions are dependent upon the action of acid hydrolase enzymes within the lysosome that can degrade lipids, carbohydrates, proteins, nucleic acids, or cellular debris. Hexosaminidase $\mathrm{A}$ is a lysosomal enzyme that converts GM2 ganglioside to G3M by removing an N-acetyl- 
glucosamine residue, thereby playing a role in the regulation of insulin sensitivity [7, 8]. In addition, cathepsin D is one of the major lysosomal proteases that contributes to the conversion of proinsulin to insulin in Langerhans cells and rat hepatocytes [9], and it is also involved in the degradation of insulin $[10,11]$.

Thiazolidinediones (TZDs), a class of drugs known to improve insulin sensitivity, are commonly used for the treatment of diabetes. TZDs are ligands for peroxisome proliferatoractivated receptors (PPAR- $\gamma$ ) and improve insulin sensitivity by lowering serum glucose and insulin levels, increasing peripheral glucose uptake, and decreasing triglyceride levels [12, 13]. In fact, studies have demonstrated the beneficial effects of TZDs in neurodegenerative diseases associated with the abnormal accumulation of protein aggregates [14-17]. One such TZD is pioglitazone (Actos), which improves hyperglycemia, reduces hyperinsulinemia, and ameliorates hypertriglyceridemia in a variety of animal models of obesity and insulin resistance [18-23]. Pioglitazone does not improve cholesterol levels in mice (personal communication, [24]).

Hypercholesterolemia is present in $70 \%$ of adults diagnosed with diabetes [25]. In T2D, serum cholesterol is elevated secondary to altered cholesterol synthesis and absorption $[26,27]$. When in excess, cholesterol is oxidized by enzymatic or reactive oxygen species (ROS)-mediated pathways. Oxidized cholesterol is increased in T2D [28, 29] and disrupt cellular membranes [30], especially lysosomal membranes [31]. Disrupted lysosomes are incapable of effectively removing ROS-damaged macromolecules [32]. This leads to a feedforward cycle of damage, where ROS promote the oxidation of cholesterol, resulting in lysosomal injury.

Alterations in lysosomal function in diabetes have been documented in the liver, kidney, heart, saliva, whole brain, and plasma [33-36]. Our previous work in the hippocampi of a well-characterized mouse model of T2D, the $\mathrm{db} / \mathrm{db}$ mouse, revealed differential expression in genes related to the lysosome [37]. Previous studies have reported alterations in the central nervous system including cognitive impairment and evidence of neurodegeneration in the $\mathrm{db} / \mathrm{db}$ mouse [38-44]. Therefore, in this study, we characterized lysosomal function in the cortex and hippocampus of the $\mathrm{db} / \mathrm{db}$ mouse. To determine a potential mechanism underlying lysosomal dysfunction in diabetes, we treated the $\mathrm{db} / \mathrm{db}$ mice with pioglitazone to ameliorate diabetes and performed subsequent in vitro studies to confirm.

\section{Materials and Methods}

\section{Animals}

Control db+ and T2D db/db mice (BKS.Cg-m +/+ Lepr ${ }^{\mathrm{db}} / \mathrm{J}$, JAX mice stock no. 000642) were purchased from the Jackson
Laboratory (Bar Harbor, ME). Mice were fed a standard rodent chow from Lab Diet (\#5053) ad libitum. For pioglitazone studies, $\mathrm{db}+$ and $\mathrm{db} / \mathrm{db}$ mice were fed a standard diet (5LOD; Research Diets, New Brunswick, NJ) supplemented with or without $112.5 \mathrm{mg}$ of pioglitazone per $\mathrm{kg}$ of chow for a final dosage of $15 \mathrm{mg} / \mathrm{kg}$ to the mouse beginning at 5 weeks of age. To document the persistence of diabetes, fasting blood glucose levels were measured every 4 weeks by analyzing one drop of tail blood after a 6-h fast using a standard Glucometer (One Touch Ultra, Milpitas, CA). Mice were euthanized at either $\sim 8$ or 20 weeks of age.

\section{Tissue Preparation}

The mice were euthanized according to our published protocols with an overdose of sodium pentobarbital, and the tissue was processed as follows per our previously published protocols [45]. For western immunoblotting analyses and enzyme activity assays, the hippocampus and cortex from the dissected brains were prepared as previously described by homogenizing the tissues in tissue protein extraction reagent (Pierce, Rockford, IL) containing a protease inhibitor cocktail (Calbiochem, San Diego, CA). For immunohistochemistry (IHC), mice were perfused with $30 \mathrm{ml}$ of $2 \%$ paraformaldehyde-lysine-periodate, the whole brains were removed and immersed in the same fixative overnight, and the brains were then cryoprotected in PBS $(0.1 \mathrm{M}, \mathrm{pH} 7.2)$ with $30 \%$ sucrose prior to embedding in OCT compound (Sakura Finetek, Torrance, CA). The brains were then sectioned $(20 \mu \mathrm{m})$ using a CM1850 cryostat (Leica Microsystems Inc., Bannockburn, IL), mounted onto SuperFrost glass slides (Fisher Scientific, Pittsburgh, PA), and stored at $-20^{\circ} \mathrm{C}$ until use. For cell fractionation and flow cytometry, the mice were perfused with 15 $\mathrm{ml} \mathrm{PBS}$, and the cortex and hippocampus were removed and immediately processed as described below.

\section{Western Immunoblotting}

Western immunoblotting was performed as previously described $[45,46]$. Briefly, the tissue lysates were either separated by SDS-PAGE and transferred to a nitrocellulose membrane or used to determine enzyme activity as described below. Trisbuffered saline with Tween-20 supplemented with $5 \%$ milk was used to block the membrane and to dilute the antibodies. Polyclonal antibodies against cathepsin D (Santa Cruz Biotechnology, Inc., Santa Cruz, CA), $\beta$-hexosaminidase (ProteinTech Group, Inc., Chicago, IL), and actin (Santa Cruz Biotechnology, Inc., Santa Cruz, CA), as well as appropriate horseradish peroxidase-conjugated secondary antibodies (Santa Cruz Biotechnology, Inc.), were used for western immunoblotting. The signal was visualized using LumiGLOenhanced chemiluminescence reagent (Cell Signaling Technology, Danvers, MA). Images were captured using 
the Chemidoc XRS system and analyzed by Quantity One software (Bio-Rad Laboratory, Hercules, CA).

\section{Enzyme Assays}

The activity of $\beta$-hexosaminidase $A$ and cathepsin $D$ was measured in 4-5 $\mu \mathrm{g}$ of protein cell lysate from the cortex and hippocampus at 8 and 20 weeks of age ( $n \geq 5$ for each group) in a 96 -well plate. To measure $\beta$-hexosaminidase $\mathrm{A}$ activity, $3.2 \mathrm{mM}$ 4-methylumbelliferyl-6-sulfo-N-acetyl- $\beta$-Dglucosaminide (MUGS) potassium salt (Santa Cruz Biotechnology, Santa Cruz, CA) was added to the cell lysate and incubated for $1 \mathrm{~h}$ at $37{ }^{\circ} \mathrm{C}$. Next, 2-amino-2-methyl-1propanol $(0.1 \mathrm{M})$ was added, and fluorescence was read immediately with a $355-\mathrm{nm}$ excitation filter and $460-\mathrm{nm}$ emission filter using a Fluoroskan Ascent II plate reader (LabSystems, Helsinki). Cathepsin D activity was assessed using the cathepsin D activity assay kit (BioVision, Mountain View, CA) according to the manufacturer's instructions. Fluorescence was read with a $320-\mathrm{nm}$ excitation filter and $460-\mathrm{nm}$ emission filter.

\section{Cell Fractionation}

Dissected cortex and hippocampus were homogenized in homogenization medium (HM: $0.32 \mathrm{M}$ sucrose, $1 \mathrm{mM}$ $\mathrm{Na}_{2}$ EDTA, 10 mM HEPES; $p H$ 7.0) and centrifuged at $800 g$ for $10 \mathrm{~min}$ at $4{ }^{\circ} \mathrm{C}$. The supernatant was kept on ice, and the pellet was resuspended in HM and centrifuged again. The supernatants from both centrifugation steps were combined and centrifuged at $20,000 \mathrm{~g}$ for $15 \mathrm{~min}$ at $4{ }^{\circ} \mathrm{C}$. The supernatant was centrifuged at $300,000 \mathrm{~g}$ for $2 \mathrm{~h}$ at $4{ }^{\circ} \mathrm{C}$ to obtain the cytosol, and the pellet was resuspended in HM and layered over a $27 \%$ Percoll solution (Sigma) diluted with Percoll diluent (2.5 M sucrose, $10 \mathrm{mM} \mathrm{Na} 2$ EDTA, $100 \mathrm{mM}$ HEPE $\mathrm{S} ; \mathrm{pH}$ 7.0). The sample was centrifuged for $95 \mathrm{~min}$ at $20,000 \mathrm{~g}$. Lysosomes were collected from the layer near the bottom of the gradient and centrifuged for $50 \mathrm{~min}$ at $100,000 \mathrm{~g}$.

\section{Measurement of Intralysosomal pH}

The measurement of intralysosomal $\mathrm{pH}$ was performed using flow cytometry with minced cortex and hippocampus (separately) that were trypsinized at $37{ }^{\circ} \mathrm{C}$ for $6 \mathrm{~min}$. The tissue was triturated with Leibovitz (L15) media, filtered $(70 \mu \mathrm{m})$, and centrifuged at $155 \mathrm{~g}$ for $5 \mathrm{~min}$ at $4{ }^{\circ} \mathrm{C}$. The pellet was resuspended in PBS. A standard curve was generated in LysoSensor Yellow/Blue DND-160 (2 mM; Invitrogen Molecular Probes) dye-loaded cell suspension using a series of phosphate-citrate buffers containing various mixtures of $300 \mathrm{mM} \mathrm{KH}_{2} \mathrm{PO}_{4}$ and $300 \mathrm{mM}$ citric acid ranging in $\mathrm{pH} 2_{-}$ 6 , supplemented with the inophores nigericin and monensin (Sigma Aldrich; $10 \mu \mathrm{mol} / \mathrm{L}$ ) to facilitate the equilibration of intralysosomal $\mathrm{pH}$ with the buffer. The cell suspension was allowed to equilibrate for $10 \mathrm{~min}$. The standard curve was generated by exciting at $355 \mathrm{~nm}$ and plotting the emission fluorescence ratio $(550 / 21 \mathrm{~nm})$ of DND-160-loaded cells as a function of the actual $\mathrm{pH}$, which was assessed on a standard $\mathrm{pH}$ meter. The intralysosomal $\mathrm{pH}$ of the lysosomes in the cortex or hippocampus from $\mathrm{db}+$ and $\mathrm{db} / \mathrm{db}$ mice was calculated by extrapolation from the standard curve.

\section{Immunohistochemistry}

Brain sections were heated on a $55{ }^{\circ} \mathrm{C}$ slide warmer for $10 \mathrm{~min}$, hydrated in PBS for $5 \mathrm{~min}$, and permeabilized with PBS containing $0.3 \%$ Triton X-100 and $3 \%$ milk. Sections were incubated in primary antibodies diluted in PBS containing $0.3 \%$ Triton X-100 and $1 \%$ BSA in a humidified chamber overnight at $22{ }^{\circ} \mathrm{C}$. A polyclonal antibody against lysosomal associated membrane protein-1 (LAMP-1; Abcam, Cambridge, MA) was used for IHC. After rinsing with PBS, sections were incubated with the appropriate secondary antibody conjugated with AlexaFluor 594 (Molecular Probes, Eugene, OR) for $1 \mathrm{~h}$ at room temperature. Following three rinses with PBS, the sections were incubated for $3 \mathrm{~h}$ at room temperature in the dark with $10 \mu \mathrm{g} / \mathrm{ml}$ filipin complex (Sigma, St. Louis, MO). After rinsing with PBS, coverslips were mounted with Prolong anti-fade mounting medium (Molecular Probes, Eugene, OR). Images were captured using a Spot-RT camera (Diagnostic Instruments Inc., Sterling Heights, MI) attached to a Nikon Microphot-FXA microscope.

\section{Primary Cortical Neuron Experiments}

Primary cortical neurons $(\mathrm{CN})$ were prepared as previously described [47]. Briefly, the cortex from E13 B6C3F1/J mice were dissected, dissociated with trypsin, and plated on poly-Llysine (PLL)-coated tissue culture plates or coverslips. CN were maintained in neurobasal media (Invitrogen, Grand Island, NY) containing $5 \mathrm{mM}$ glucose, supplemented with $1 \times$ B27 (without antioxidant; Invitrogen), antibiotics (penicillin, streptomycin, and neomycin; Sigma), $2.5 \mu \mathrm{g} / \mathrm{ml}$ albumin, $10 \mu \mathrm{g} / \mathrm{ml}$ apo-transferrin, $0.1 \mu \mathrm{g} / \mathrm{ml}$ biotin, $15 \mu \mathrm{g} / \mathrm{ml}$ D-galactose, $7 \mathrm{ng} / \mathrm{ml}$ progesterone, $16 \mu \mathrm{g} / \mathrm{ml}$ putrescine, $4 \mathrm{ng} / \mathrm{ml} \mathrm{se}$ lenium, $3 \mathrm{ng} / \mathrm{ml} \beta$-estradiol, $4 \mathrm{ng} / \mathrm{ml}$ hydrocortisone, $3 \mu \mathrm{g} / \mathrm{ml}$ catalase, and $2.5 \mu \mathrm{g} / \mathrm{ml}$ superoxide dismutase. $\mathrm{CN}$ were cultured for 6 days prior to use, with an addition of fresh media on day 3. $\mathrm{CN}$ treatment media (neurobasal media without B27 and antibiotics) was used to carry out the experiments indicated below.

In vitro experiments involved treating primary $\mathrm{CN}$ with $25 \mathrm{mM}$ of glucose [47] with or without $5 \mu \mathrm{M}$ oxidized cholesterol (27-hydroxycholesterol; Medical Isotopes, Inc., Pelham, NH; Prasanthi et al. 2009) for 72 h. Lysosomal destabilization was measured using acridine orange (AO), a 
lysosomotropic weak base, and metachromatic fluorochrome. Briefly, $5 \mu \mathrm{g} / \mathrm{ml} \mathrm{AO}$ in neurobasal medium was incubated with $\mathrm{CN}$ on coverslips for $15 \mathrm{~min}$ at $37{ }^{\circ} \mathrm{C}$. After the cells were washed and treated as outlined above, microscopic assessment of lysosomes was performed using an Olympus IC71 inverted confocal microscope and FluoView v4.3 software. Quantitative analysis was performed after staining and treatment of $\mathrm{CN}$ in a 96-well clear bottom/black walled plate using a Fluoroskan Ascent FL instrument. When excited by a blue light $(450 \mathrm{~nm})$, AO fluoresces red (612-nm wavelength emission) at high lysosomal concentrations and green (520$\mathrm{nm}$ wavelength emission) at low nuclear and cytosolic concentrations. Rupture of AO-loaded lysosomes shows an increase in cytoplasmic diffuse green fluorescence and a decrease in granular red fluorescence $[48,49]$.

\section{Statistical Analyses}

Data analyses were performed using Prism v6 (GraphPad Software, Inc.). Assumptions about Gaussian distribution of data were made using the D'Agostino and Pearson omnibus normality test. Data not corresponding to a Gaussian distribution were analyzed using an appropriate mathematical transformation, $\log (x)$. At least 10 mice per group at 8 and 20 weeks of age were used for metabolic studies. For all other measures, at least 5 mice per group were used. $t$ test was used in experiments where T2D was compared to the nondiabetic control. For all experiments, ${ }^{*} p<0.05,{ }^{* *} p<0.01, \# p<0.001$, and $\Phi p<0.0001$ and bar graphs illustrate the mean \pm standard error of the mean (SEM).

\section{Results}

\section{Cortical and Hippocampal Changes in Hexosaminidase A Protein Expression and Activity in T2D}

We evaluated the lysosomal enzyme $\beta$-hexosaminidase $\mathrm{A}$ to examine lysosomal function in T2D. While hexosaminidase A protein expression did not change in the cortex, it was significantly increased in the hippocampus by $33 \%$ at 8 weeks and $28 \%$ at 20 weeks in T2D compared to the nondiabetic control (Fig. 1a, b). Likewise, the activity of hexosaminidase A did not change in the cortex; however, it decreased by $10 \%$ in the hippocampus of T2D mice at 8 weeks of age and increased by $8 \%$ in the hippocampus of T2D mice at 20 weeks of age compared to the nondiabetic control (Fig. 1c, d).

\section{Cortical and Hippocampal Changes in Cathepsin D Protein Expression and Activity in T2D}

To further examine lysosomal function in $\mathrm{T} 2 \mathrm{D}$, the protein expression and activity of the major lysosomal protease, cathepsin D, were also evaluated. The protein expression of cathepsin D in T2D mice significantly increased by $55 \%$ at 8 weeks and $118 \%$ at 20 weeks in the cortex, and by $46 \%$ at 8 weeks and $64 \%$ at 20 weeks in the hippocampus, compared to nondiabetic control (Fig. 2a, b). This increase in protein expression in the cortex at 20 weeks of age was associated with a $21 \%$ decrease in the activity of cathepsin D in T2D compared to the nondiabetic control, whereas the activity of cathepsin D did not change in the hippocampus (Fig. 2c, d).

The processing of cathepsin D in the Golgi, endosomes, and lysosomes correspond to the 3 major forms-immature, intermediate, and mature, respectively. Alterations in the activity of cathepsin $\mathrm{D}$ are associated with the mature form of the protein. Since the protein expression of cathepsin D is significantly increased in the cortex of T2D but the activity is decreased, we assessed the 3 major forms of cathepsin D in the cortex to evaluate whether or not T2D alters the trafficking pattern of cathepsin D. We observed a significant increase in both the intermediate and mature forms of cathepsin D in T2D compared to the nondiabetic control (Fig. 2e, f).

\section{Lysosomal Membrane Integrity, But Not pH, Is Compromised in T2D}

The activity of cathepsin D was expected to parallel the direction of the protein expression of the mature form of cathepsin D; however, we observed a decrease in the activity with an increase in the protein expression of the mature form of cathepsin $\mathrm{D}$ in the $\mathrm{T} 2 \mathrm{D} \mathrm{db} / \mathrm{db}$ mouse cortex. This may be due to either a compromised lysosomal membrane with subsequent leakage of the mature form of cathepsin D into the cytosol, or an alteration in intralysosomal $\mathrm{pH}$ in the $\mathrm{db} / \mathrm{db}$ mouse cortex that renders mature cathepsin D inactive. Thus, western immunoblotting following cell fractionation was used to assess the integrity of lysosomal membranes in T2D. The protein expression of both lysosomal enzymes hexsoaminidase A and cathepsin D in the cytosol was increased by at least $100 \%$ in the $\mathrm{db} / \mathrm{db}$ mouse hippocampus/cortex compared with the nondiabetic control (Fig. 3a, c), whereas the protein expression levels of the lysosomal enzymes were not significantly different in the lysosomal fraction of $\mathrm{db} / \mathrm{db}$ mice compared with the nondiabetic control (Fig. 3b, d). Flow cytometry was then utilized to assess the potential alterations in the intralysosomal $\mathrm{pH}$ in $\mathrm{T} 2 \mathrm{D}$ cortex and hippocampus. The average intralysosomal $\mathrm{pH}$ in the cortex of the $d b+$ and $d b / d b$ mice was $4.75 \pm 0.87$ and $4.71 \pm 1.1$, respectively (data not shown). Similarly, the average intralysosomal $\mathrm{pH}$ in the hippocampus of the $\mathrm{db}+$ and $\mathrm{db} / \mathrm{db}$ mice was $4.75 \pm 0.39$ and $4.68 \pm 0.39$, respectively (data not shown). 
Fig. 1 Protein expression and activity of the lysosomal enzyme hexosaminidase $\mathrm{A}$ in the brain of T2D mice. a, b Protein expression and $\mathbf{c}, \mathbf{d}$ activity of

hexosaminidase $\mathrm{A}$ in the cortex (a, c) and hippocampus (b, d) of $\mathrm{db}+$ and $\mathrm{db} / \mathrm{db}$ mice at 8 and 20 weeks of age. Actin was used as the loading control $\left({ }^{*} p<0.05\right.$ and $* * p<0.01$ compared with $\mathrm{db}+; n \geq 6$ ). Activity is expressed in relative fluorescence units (RFU)

\section{Cortex}
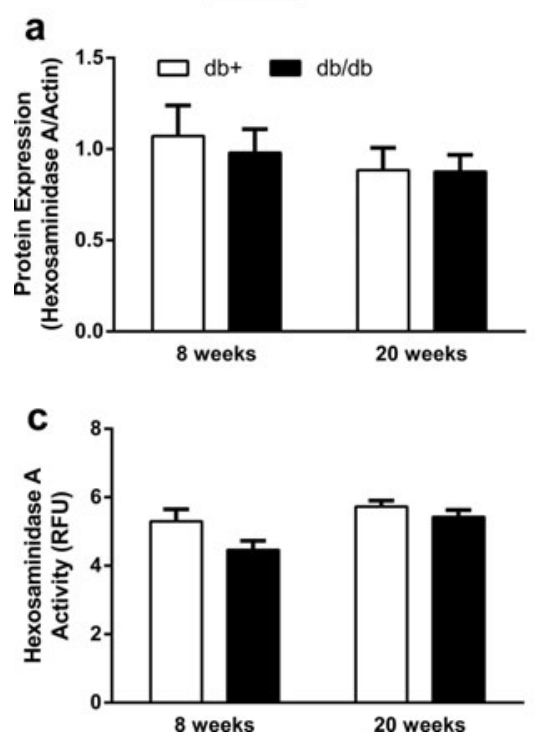

Hippocampus
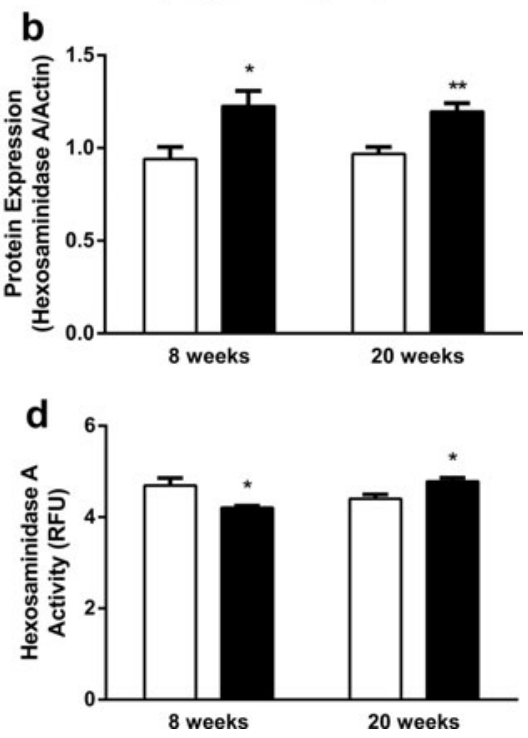

Elevated Levels of Glucose Can Cause Destabilization of the Lysosomal Membrane

To determine a potential mechanism underlying the lysosomal destabilization and leakage associated with T2D, AO staining was used on live primary $\mathrm{CN}$ cultures in the presence or absence of $25 \mathrm{mM}$ glucose treatment. An increase in the green cytosolic fluorescence and/or a decrease in red punctate lysosomes are indicative of a loss of membrane integrity. Microscopy of live cells revealed that $25 \mathrm{mM}$ of glucose treatment for $72 \mathrm{~h}$ led to the loss of red lysosomal staining (Fig. 4).
Fig. 2 Protein expression and activity of the major lysosomal protease cathepsin $\mathrm{D}$ in the brain of T2D mice. a, $\mathbf{b}$ Protein expression and $\mathbf{c}, \mathbf{d}$ activity of cathepsin D in the cortex $(\mathbf{a}, \mathbf{c})$ and hippocampus $(\mathbf{b}, \mathbf{d})$ of $\mathrm{db}+$ and $\mathrm{db} / \mathrm{db}$ mice at 8 and 20 weeks of age. e Representative immunoblot and $\mathbf{f}$ densitometric analysis of the protein expression and subcellular distribution of cathepsin D in the cortex. Actin was used as the loading control $\left({ }^{*} p<0.05,{ }^{* *} p<0.01, \# p<0.01\right.$, and $\Phi p<0.0001$ compared with $\mathrm{db}+; n \geq 6$ ). Activity is expressed in relative fluorescence units (RFU)
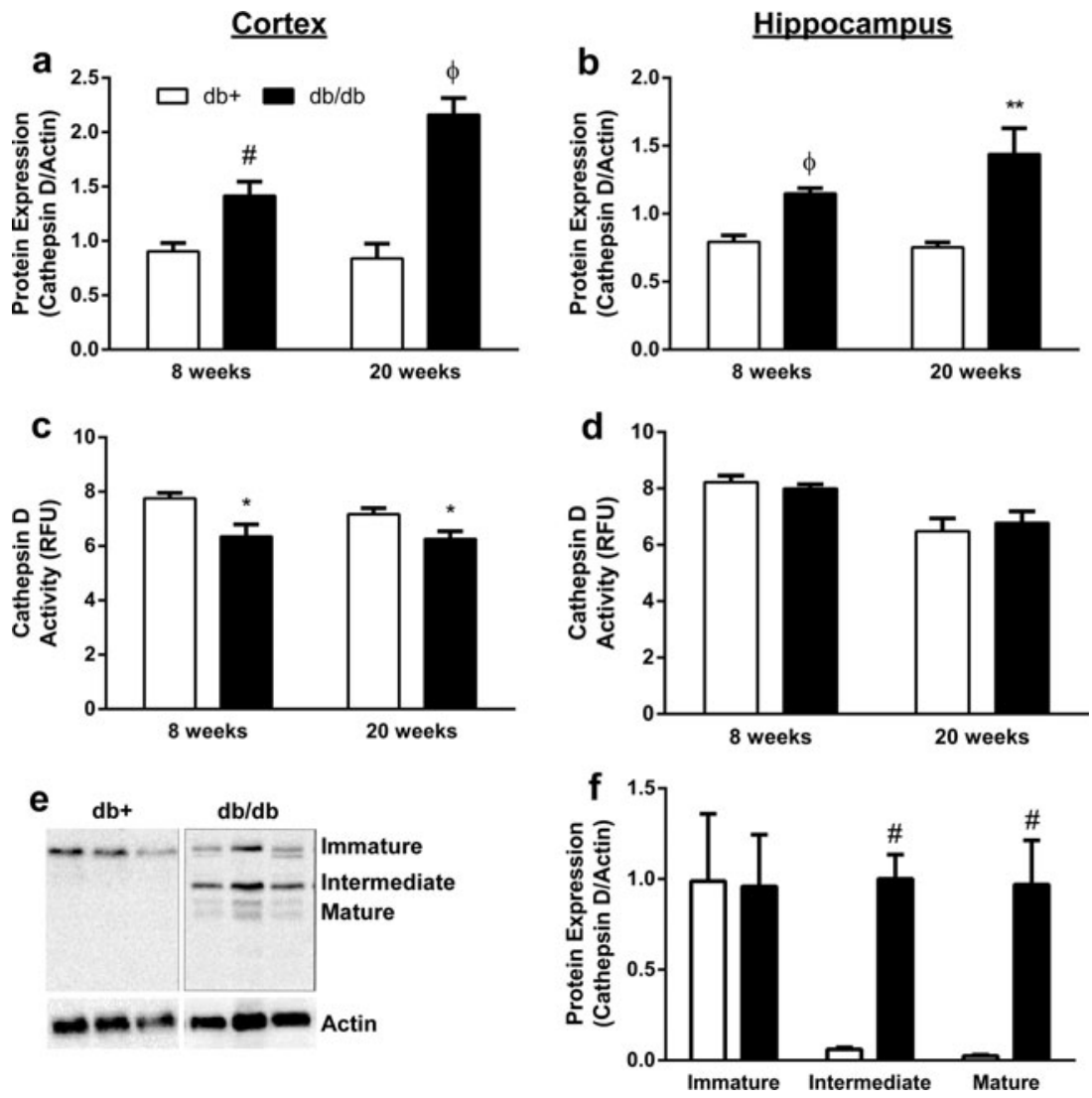
Fig. 3 Hexosaminidase A and cathepsin D levels in the hippocampus/cortex of T2D mouse brains. Cell fractionation was utilized to isolate the cytosolic and lysosomal fraction from the hippocampus/cortex of T2D mice at 20 weeks of age. a, b The levels of hexosaminidase A and $\mathbf{c}, \mathbf{d}$ cathepsin $\mathrm{D}$ in the cytosolic (a, c) and the lysosomal fraction $(\mathbf{b}, \mathbf{d})$ from the hippocampus/cortex of $\mathrm{db}+$ and $\mathrm{db} / \mathrm{db}$ mice. Actin was used as the loading control $(* p<0.05$ compared with $\mathrm{db}+; n \geq 6$ )
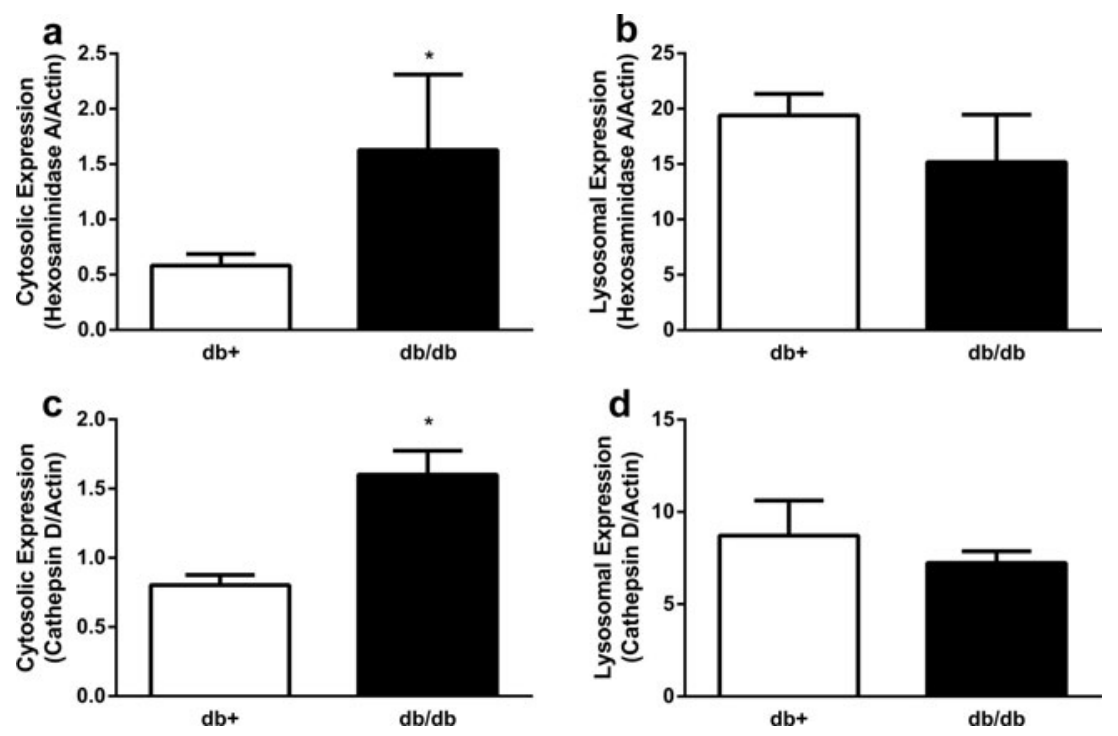

\section{Pioglitazone Improves the Hyperglycemic Phenotype But Not Alterations in Lysosomal Membrane Integrity Associated with T2D}

Pioglitazone treatment worsens the obesity phenotype of $\mathrm{db} /$ $\mathrm{db}$ mice and also significantly increases the weight of $\mathrm{db}+$ mice; however, it reverses the elevated levels of blood glucose, glycosylated hemoglobin, and triglycerides in $\mathrm{db} / \mathrm{db}$ mice back to levels similar to those in control $\mathrm{db}+$ mice (personal communication, [24]). Thus, to determine if pioglitazone can effectively reverse the leakage of lysosomal enzymes into the cytosol, the protein expression levels of hexoaminidase $\mathrm{A}$ and cathepsin $\mathrm{D}$ were evaluated following pioglitazone treatment in $\mathrm{db}+$ and $\mathrm{db} / \mathrm{db}$ mice. While pioglitazone did not alter the total protein expression levels of
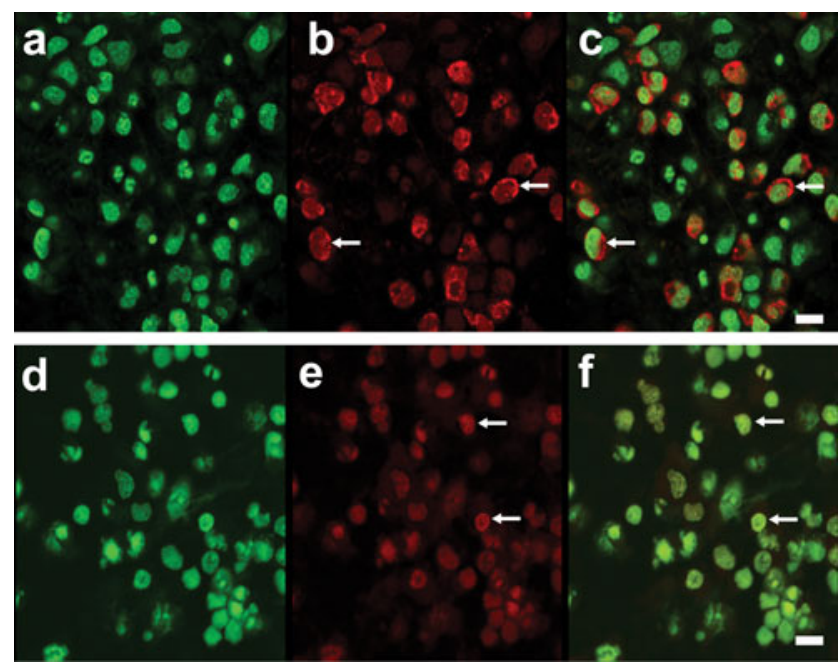

Fig. 4 AO staining in $\mathrm{CN}$ treated with glucose. a-c Representative images of control $\mathrm{CN}$ and $\mathbf{d}-\mathbf{f}$ and $\mathrm{CN}$ treated with $25 \mathrm{mM}$ glucose for $72 \mathrm{~h}$. Nuclei are stained; green and red puncta represent lysosomes (white arrows). Scale bar represents $25 \mu \mathrm{m}$ hexosaminidase A or cathepsin D (data not shown), pioglitazone treatment did elevate the levels of cathepsin $D$ in the cytosol following cell fractionation (Fig. 5).

\section{Elevated Levels of Cholesterol Within Lysosomes in T2D}

Fast protein liquid chromatography analyses indicate that pioglitazone treatment does not reverse the levels of cholesterol and promotes an increase in the low density lipoprotein (LDL) cholesterol fraction in $\mathrm{db} / \mathrm{db}$ mice compared to nondiabetic controls [24]. Thus, to evaluate cholesterol load in the lysosomes of $\mathrm{db} / \mathrm{db}$ mice, fillipin staining was used. We observed an increase in the colocalization of fillipin and the lysosomal membrane protein LAMP-1 in the cortex and hippocampus of $\mathrm{db} / \mathrm{db}$ mice compared with $\mathrm{db}+$ control mice (Fig. 6).

\section{Cholesterol Can Cause Destabilization of the Lysosomal Membrane}

To investigate cholesterol as a potential mediator underlying the destabilization and leakage of lysosomes associated with $\mathrm{T} 2 \mathrm{D}$, AO staining was used in live $\mathrm{CN}$ treated with and without oxidized cholesterol. Quantitative analysis of the AO staining of live $\mathrm{CN}$ revealed that oxidized cholesterol treatment for $72 \mathrm{~h}$ led to an increase in green fluorescence and a decrease in the red lysosomal staining (Fig. 7).

\section{Discussion}

In the current study, we investigated the mechanisms underlying alterations in lysosomal function induced by diabetes. Hyperglycemia is a key player in many complications associated with diabetes. Thus, according to the American Diabetes Association, tight glycemic control with either drugs or diet 


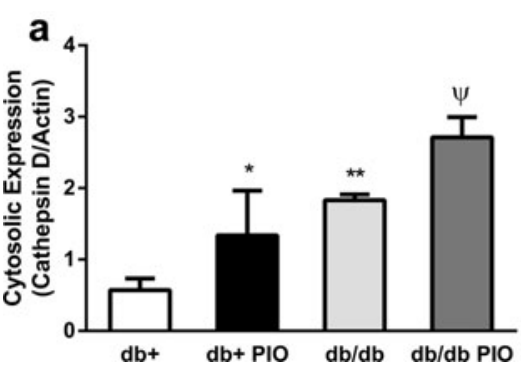

Fig. 5 Levels of cathepsin D following treatment with pioglitazone in T2D mice Levels of cathepsin D in the a cytosolic fraction and $\mathbf{b}$ lysosomal fraction of hippocampus and cortex from $\mathrm{db}+$ and $\mathrm{db} / \mathrm{db}$ mice

and exercise is the most effective method for preventing diabetic complications. We show for the first time that cholesterol, and not hyperglycemia, may mediate the changes observed in lysosomal function during diabetes in the hippocampus/ cortex. Abnormalities in the lysosomal system are early manifestations of neurodegeneration [4]; thus, altered cholesterol metabolism may play a role in diabetes-induced lysosomal changes and neurodegeneration.

The expression of both hexosaminidase A and cathepsin D is upregulated in neurodegenerative diseases [50-53]. Hexosaminidase A removes $\mathrm{N}$-acetyl-glucosamine residue from GM2 ganglioside, converting it to GM3. Obesity leads to a dramatic increase in the protein levels of GM2 in adipose tissue in a mouse model of T2D [54]. Hence, the increase in protein expression observed in the hippocampus of the $\mathrm{db} / \mathrm{db}$ mouse may be due to obesity. Consistent with our observed increase in hexosaminidase A activity in the $\mathrm{db} / \mathrm{db}$ mouse hippocampus, T2D patients have increased activity of hexosaminidase A in plasma and serum [36]. Thus, increased activity of hexosaminidase A in plasma and peripheral blood mononuclear cells may have diagnostic value for the detection of the early stages of dementia in Alzheimer's disease (AD) patients with and without T2D [36].

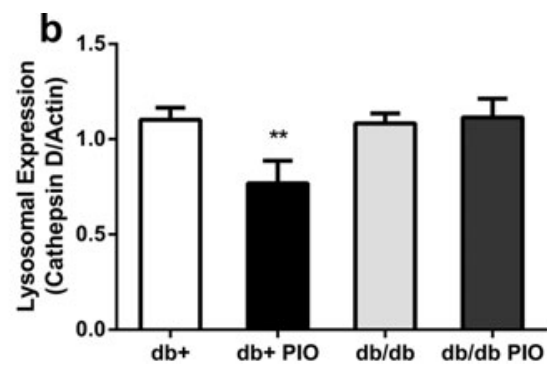

treated with and without pioglitazone (PIO) at 16 weeks of age. ${ }^{*} p<0.05$, ${ }^{* *} p<0.01, \# p<0.01$, and $\Phi p<0.0001$ compared with $\mathrm{db}+; n \geq 6$

Cathepsin D is the major lysosomal protease in neurons, contributing to nearly $90 \%$ of protease degradation in the brain [55]. The increase in protein expression we observed in both the cortex and hippocampus is consistent with previous studies in T2D patients reporting that the expression of cathepsin D is increased in serum and leucocytes [56, 9]. On the other hand, the decrease in the activity of cathepsin D we observed is unique to our studies in T2D and may be indicative of abnormalities in the trafficking of cathepsin D to lysosomes. The trafficking of cathepsin D was assessed by evaluating the 3 different isoforms -immature, intermediate, and mature-which correspond to trafficking from the Golgi, endosomes, and lysosomes, respectively [57]. The acidic environment of lysosomes provides a platform for proteolytic cleavage of the intermediate form of cathepsin $\mathrm{D}$ to the mature form [57]. Thus, any alterations in the $\mathrm{pH}$ of lysosomes may impact the levels of the mature form of the enzyme. Our data indicate that the $\mathrm{pH}$ within lysosomes is not altered during T2D. Alternatively, the elevated levels of cathepsin D in the cytosolic fraction in $\mathrm{db} / \mathrm{db}$ mice suggests that the lysosomal membrane may be compromised. This would explain the elevated protein levels of cathepsin $\mathrm{D}$ and the decrease in the activity due to lack of acidic $\mathrm{pH}$ in the cytosol. The
Fig. 6 Cholesterol accumulation within lysosomes of T2D mice. Representative images of hippocampus colabeled with filipin (green), which stains cholesterol, and LAMP-1 (red), which stains lysosomes, in a-c $\mathrm{db}+$ and $\mathbf{d}-\mathbf{f} \mathrm{db} / \mathrm{db}$ mice. Areas of colocalization (yellow) demonstrate cholesterol accumulation within lysosomes (asterisks). Scale bar represents $10 \mu \mathrm{m}$
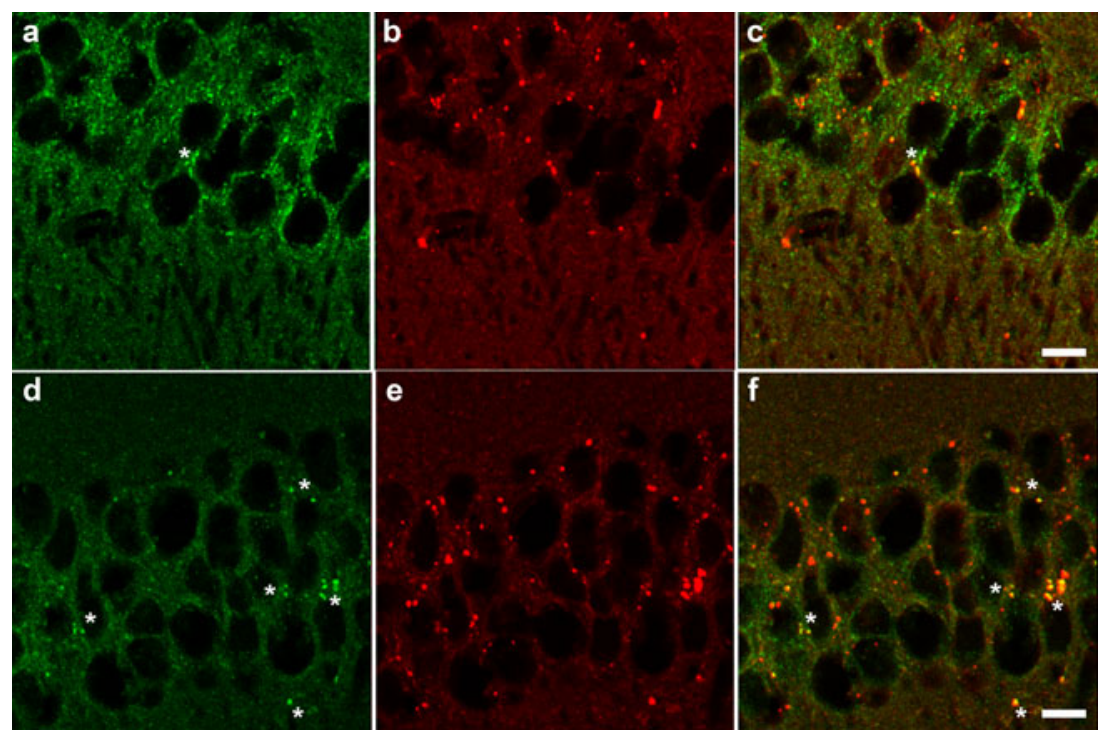
Fig. $7 \mathrm{CN}$ treatment with oxidized cholesterol and $\mathrm{AO}$ Fluroskan analysis of green and red fluorescence at $\mathbf{a}$ time 0 and $\mathbf{b}$ after treatment with control DMSO or oxidized cholesterol for $72 \mathrm{~h}$. Fluorescence is represented by arbitrary units (A.U.). $\mathbf{c}, \mathbf{d}$ Images are representative of $\mathrm{AO}$ staining following $72 \mathrm{~h}$ of $\mathbf{c}$ control DMSO or $\mathbf{d}$ oxidized cholesterol treatment, where nuclei are stained green and red puncta represent lysosomes. $* * p<0.01$ compared with control DMSO. Scale bar represents $50 \mu \mathrm{m}$
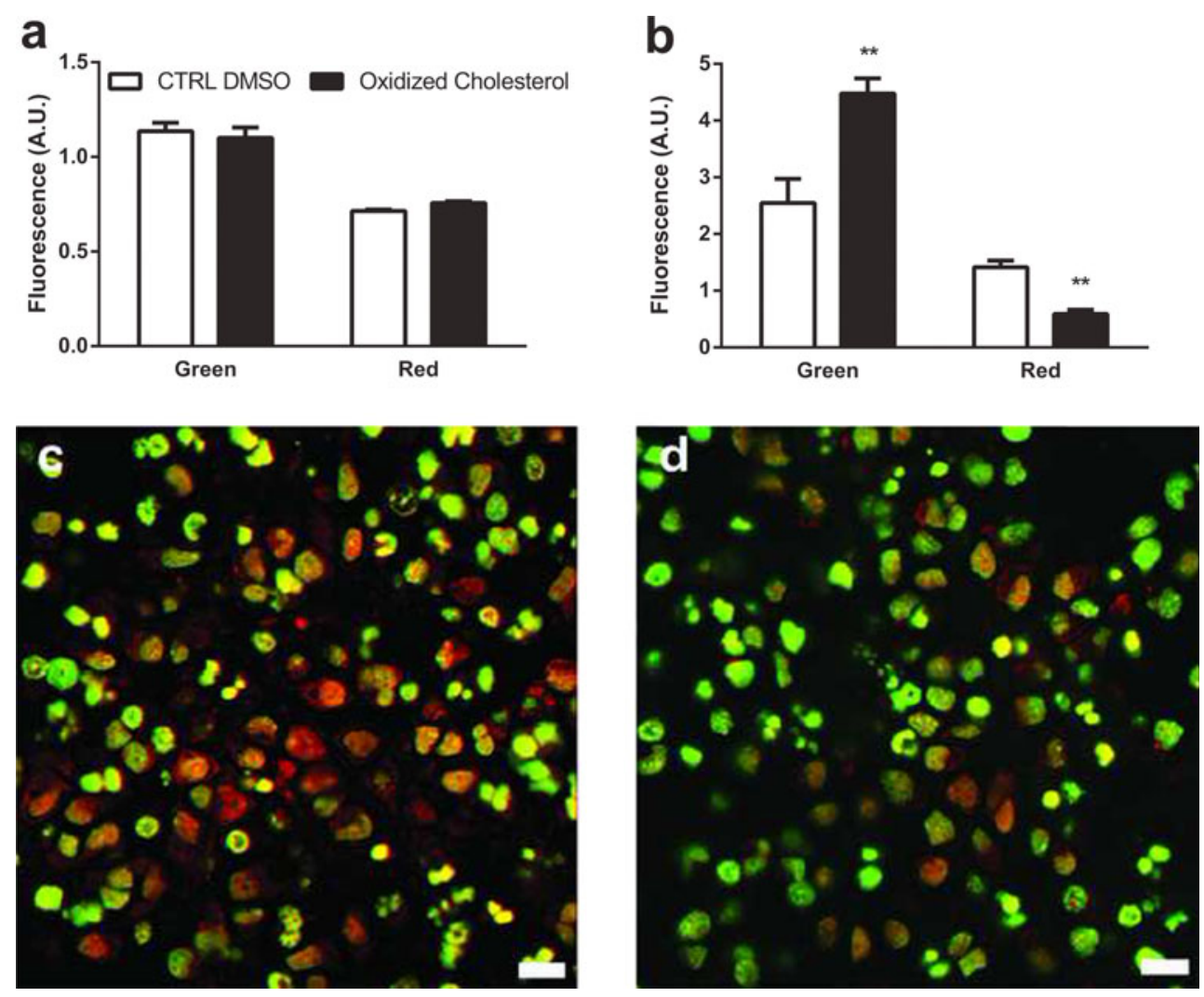

mechanism underlying this damage to the membrane of lysosomes is not known; however, oxidative stress is associated with leakage of cathepsin D into the cytosol from the lysosome in both in vivo and in vitro models [58, 59].

Hyperglycemia is the key player leading to oxidative stress during T2D. To investigate hyperglycemia as the mechanism underlying lysosomal membrane damage, we exposed $\mathrm{CN}$ to hyperglycemic conditions, demonstrating that hyperglycemia causes destabilization of the lysosomal membrane. A previous study demonstrated that hyperglycemia inhibited lysosomal function in macrophages and may contribute to diabetesassociated atherosclerosis [60]. Thus, reversing hyperglycemia may have a profound impact on lysosomal membrane stability.

Pioglitazone is known to improve hyperglycemia, reduce hyperinsulinemia, and ameliorate hypertriglyceridemia in a variety of animal models of obesity and insulin resistance [22, 21, 20, 19, 18]; however, pioglitazone did not reverse the alterations in lysosomal enzymes and in fact lead to a further increase in the levels of cathepsin D in the cytosol. We previously demonstrated that pioglitazone does not improve hypercholesterolemia in $\mathrm{db} / \mathrm{db}$ mice [24]. In addition, in patients with T2D, serum cholesterol is elevated secondary to altered cholesterol synthesis and absorption [27, 26]. When in excess, cholesterol is oxidized by enzymatic or reactive oxygen species-mediated pathways to generate cholesterol oxides. Cholesterol oxide derivatives, known as oxysterols, are common components of oxidized LDLs, are increased in T2D [29, 28], and disrupt lysosomal membranes [31]. We demonstrate that oxysterols are capable of disrupting lysosomal membranes in primary $\mathrm{CN}$. Thus, it is possible that pioglitazone did not improve the T2D-induced effects on lysosomes due to its inability to reverse hypercholesterolemia in $\mathrm{db} / \mathrm{db}$ mice.

In summary, it is likely that multiple mechanisms contribute to the alterations in lysosomal enzymes during diabetes. We demonstrate that improving hyperglycemia, insulin resistance, and hypertriglyceridemia alone is not sufficient to reverse diabetes-induced changes in lysosomal membrane stability, although our studies further demonstrate that hypercholesterolemia plays a role in lysosomal membrane destabilization. Future studies will focus on cholesterol as a potential therapeutic target to reverse or prevent the impact of T2D on lysosomal enzymes.

Acknowledgments The authors wish to acknowledge Drs. Stacey A. Sakowski and Anne Heacock for expert editorial advice, Carey Backus and Janet Boggs for technical assistance, and the University of Michigan Flow Cytometry Core.

Funding This work was supported by the National Institutes of Health (NIA Training Grant T32 AG000114, to C. S-R.; NINDS Neurology Training Grant T32 NS007222, to C. S-R.; and the Animal Models of Diabetic Complications Consortium NIH U01-DK076160), the A. Alfred Taubman Medical Research Institute, and the Program for Neurology 
Research and Discovery. This work also utilized the Chemistry Core of the Michigan Diabetes Research and Training Center (funded by NIDDK DK020572).

Conflict of Interest The authors declare that they have no conflict of interest.

Compliance with Ethical Standards All protocols and procedures were approved by the University of Michigan Committee on the Use and Care of Animals (UCUCA; approval number PRO00003694), and are in compliance with the University guidelines, State and Federal regulations, and the standards of the "Guide for the Care and Use of Laboratory Animals." The University's Animal Welfare Assurance Number on file with NIH Office of Laboratory Animal Welfare (OLAW) is A311401 , and the University is accredited by the Association for the Assessment and Accreditation of Laboratory Animal Care International (AAALAC, Intl.).

Open Access This article is distributed under the terms of the Creative Commons Attribution 4.0 International License (http:// creativecommons.org/licenses/by/4.0/), which permits unrestricted use, distribution, and reproduction in any medium, provided you give appropriate credit to the original author(s) and the source, provide a link to the Creative Commons license, and indicate if changes were made.

\section{References}

1. Li L, Holscher C (2007) Common pathological processes in Alzheimer disease and type 2 diabetes: a review. Brain Res Rev 56(2):384-402. doi:10.1016/j.brainresrev.2007.09.001

2. Biessels GJ, ter Laak MP, Hamers FP, Gispen WH (2002) Neuronal $\mathrm{Ca} 2+$ disregulation in diabetes mellitus. Eur J Pharmacol 447(2-3): 201-209

3. Franke K, Gaser C, Manor B, Novak V (2013) Advanced BrainAGE in older adults with type 2 diabetes mellitus. Front Aging Neurosci 5:90. doi:10.3389/fnagi.2013.00090

4. Zhang L, Sheng R, Qin Z (2009) The lysosome and neurodegenerative diseases. Acta Biochim Biophys Sin 41(6):437-445

5. Cuervo AM, Dice JF (2000) When lysosomes get old. Exp Gerontol 35(2):119-131

6. Nixon RA, Yang DS, Lee JH (2008) Neurodegenerative lysosomal disorders: a continuum from development to late age. Autophagy 4(5):590-599

7. Tagami S, Inokuchi Ji J, Kabayama K, Yoshimura H, Kitamura F, Uemura S, Ogawa C, Ishii A et al (2002) Ganglioside GM3 participates in the pathological conditions of insulin resistance. J Biol Chem 277(5):3085-3092. doi:10.1074/jbc.M103705200

8. Yamashita T, Hashiramoto A, Haluzik M, Mizukami H, Beck S, Norton A, Kono M, Tsuji S et al (2003) Enhanced insulin sensitivity in mice lacking ganglioside GM3. Proc Natl Acad Sci U S A 100(6):3445-3449. doi:10.1073/pnas.0635898100

9. Llorente L, De La Fuente H, Richaud-Patin Y, Alvarado-De La Barrera C, Diaz-Borjon A, Lopez-Ponce A, Lerman-Garber I, Jakez-Ocampo J (2000) Innate immune response mechanisms in non-insulin dependent diabetes mellitus patients assessed by flow cytoenzymology. Immunol Lett 74(3):239-244

10. Duckworth WC, Hamel FG, Peavy DE (1988) Hepatic metabolism of insulin. Am J Med 85(5A):71-76

11. Valera Mora ME, Scarfone A, Calvani M, Greco AV, Mingrone G (2003) Insulin clearance in obesity. J Am Coll Nutr 22(6):487-493

12. Saltiel AR, Olefsky JM (1996) Thiazolidinediones in the treatment of insulin resistance and type II diabetes. Diabetes 45(12):16611669
13. Kahn CR, Chen L, Cohen SE (2000) Unraveling the mechanism of action of thiazolidinediones. J Clin Invest 106(11):1305-1307. doi: 10.1172/JCI11705

14. Searcy JL, Phelps JT, Pancani T, Kadish I, Popovic J, Anderson KL, Beckett TL, Murphy MP et al (2012) Long-term pioglitazone treatment improves learning and attenuates pathological markers in a mouse model of Alzheimer's disease. J Alzheimer's Dis: JAD 30(4):943-961. doi:10.3233/JAD-2012-111661

15. Liu C, Feng T, Zhu N, Liu P, Han X, Chen M, Wang X, Li N et al (2015) Identification of a novel selective agonist of PPARgamma with no promotion of adipogenesis and less inhibition of osteoblastogenesis. Sci Reports 5:9530. doi:10.1038/srep09530

16. Hanyu H, Sato T, Sakurai H, Iwamoto T (2010) The role of tumor necrosis factor-alpha in cognitive improvement after peroxisome proliferator-activator receptor gamma agonist pioglitazone treatment in Alzheimer's disease. J Am Geriatr Soc 58(5):1000-1001. doi:10.1111/j.1532-5415.2010.02841.x

17. Chiang MC, Chern Y, Huang RN (2012) PPARgamma rescue of the mitochondrial dysfunction in Huntington's disease. Neurobiol Dis 45(1):322-328. doi:10.1016/j.nbd.2011.08.016

18. Yki-Jarvinen H (2004) Thiazolidinediones. N Engl J Med 351(11): 1106-1118. doi:10.1056/NEJMra041001

19. Saltiel AR (2001) New perspectives into the molecular pathogenesis and treatment of type 2 diabetes. Cell 104(4):517-529

20. Nolan JJ, Ludvik B, Beerdsen P, Joyce M, Olefsky J (1994) Improvement in glucose tolerance and insulin resistance in obese subjects treated with troglitazone. N Engl J Med 331(18):11881193. doi:10.1056/NEJM199411033311803

21. Mauvais-Jarvis F, Kahn CR (2000) Understanding the pathogenesis and treatment of insulin resistance and type 2 diabetes mellitus: what can we learn from transgenic and knockout mice? Diabetes Metabolism 26(6):433-448

22. Kemnitz JW, Elson DF, Roecker EB, Baum ST, Bergman RN, Meglasson MD (1994) Pioglitazone increases insulin sensitivity, reduces blood glucose, insulin, and lipid levels, and lowers blood pressure, in obese, insulin-resistant rhesus monkeys. Diabetes 43(2):204-211

23. Bowen L, Stein PP, Stevenson R, Shulman GI (1991) The effect of CP 68,722 , a thiozolidinedione derivative, on insulin sensitivity in lean and obese Zucker rats. Metab Clin Exp 40(10):1025-1030

24. 2014 annual meetings (2014) Annals of neurology 76(Suppl 18): S1-S254. doi:10.1002/ana.24247

25. Harris MI (1991) Hypercholesterolemia in diabetes and glucose intolerance in the U.S. population. Diabetes Care 14(5):366-374

26. Simonen PP, Gylling HK, Miettinen TA (2002) Diabetes contributes to cholesterol metabolism regardless of obesity. Diabetes Care 25(9):1511-1515

27. Miettinen TA, Gylling H, Tuominen JA, Simonen P, Koivisto V (2004) Absorption and synthesis of cholesterol in patients with type 1 and type2 diabetes mellitus. Duodecim 120(6):721-723

28. Murakami H, Tamasawa N, Matsui J, Yasujima M, Suda T (2000) Plasma oxysterols and tocopherol in patients with diabetes mellitus and hyperlipidemia. Lipids 35(3):333-338

29. Ferderbar S, Pereira EC, Apolinario E, Bertolami MC, Faludi A, Monte O, Calliari LE, Sales JE et al (2007) Cholesterol oxides as biomarkers of oxidative stress in type 1 and type 2 diabetes mellitus. Diabetes Metab Res Rev 23(1):35-42. doi:10.1002/dmrr.645

30. Roussi S, Gosse F, Aoude-Werner D, Zhang X, Marchioni E, Geoffroy P, Miesch M, Raul F (2007) Mitochondrial perturbation, oxidative stress and lysosomal destabilization are involved in 7beta-hydroxysitosterol and 7beta-hydroxycholesterol triggered apoptosis in human colon cancer cells. Apoptosis: An Int J programmed Cell Death 12(1):87-96. doi:10.1007/ s10495-006-0485-y 
31. Li W, Dalen H, Eaton JW, Yuan XM (2001) Apoptotic death of inflammatory cells in human atheroma. Arterioscler Thromb Vasc Biol 21(7):1124-1130

32. Terman A, Brunk UT (2006) Oxidative stress, accumulation of biological 'garbage', and aging. Antioxidants Redox Signal 8(12):197-204. doi:10.1089/ars.2006.8.197

33. Belfiore F, Rabuazzo AM, Iannello S, Campione R, Vasta D (1985) Cathepsin D and other hydrolases in the kidney of streptozotocindiabetic mice. Possible relevance to microangiopathy. Hormone Metab Res 17(9):435-437. doi:10.1055/s-2007-1013570

34. Chua BH, Long WM, Lautensack N, Lins JA, Morgan HE (1983) Effects of diabetes on cardiac lysosomes and protein degradation. Am J Physiol 245(1):C91-100

35. Knas M, Karaszewska K, Szajda SD, Zarzycki W, Dudzik D, Zwierz K (2006) Saliva of patients with Type 1 diabetes: effect of smoking on activity of lysosomal exoglycosidases. Oral Dis 12(3): 278-282. doi:10.1111/j.1601-0825.2005.01190.x

36. Tiribuzi R, Orlacchio A, Crispoltoni L, Maiotti M, Zampolini M, De Angeliz M, Mecocci P, Cecchetti R et al (2011) Lysosomal betagalactosidase and beta-hexosaminidase activities correlate with clinical stages of dementia associated with Alzheimer's disease and type 2 diabetes mellitus. J Alzheimer's Dis: JAD 24(4):785797. doi:10.3233/JAD-2011-100525

37. Sims-Robinson C, Zhao S, Hur J, Feldman EL (2012) Central nervous system endoplasmic reticulum stress in a murine model of type 2 diabetes. Diabetologia 55(8):2276-2284. doi:10.1007/ s00125-012-2573-6

38. Zhao Q, Niu Y, Matsumoto K, Tsuneyama K, Tanaka K, Miyata T, Yokozawa T (2012) Chotosan ameliorates cognitive and emotional deficits in an animal model of type 2 diabetes: possible involvement of cholinergic and VEGF/PDGF mechanisms in the brain. BMC Complement Alternativ Med 12:188. doi:10.1186/1472-6882-12188

39. Zhao Q, Matsumoto K, Tsuneyama K, Tanaka K, Li F, Shibahara N, Miyata T, Yokozawa T (2011) Diabetes-induced central cholinergic neuronal loss and cognitive deficit are attenuated by tacrine and a Chinese herbal prescription, kangen-karyu: elucidation in type 2 diabetes $\mathrm{db} / \mathrm{db}$ mice. J Pharmacol Sci 117(4):230-242

40. Stranahan AM, Arumugam TV, Cutler RG, Lee K, Egan JM, Mattson MP (2008) Diabetes impairs hippocampal function through glucocorticoid-mediated effects on new and mature neurons. Nat Neurosci 11(3):309-317. doi:10.1038/nn2055

41. Ramos-Rodriguez JJ, Ortiz O, Jimenez-Palomares M, Kay KR, Berrocoso E, Murillo-Carretero MI, Perdomo G, Spires-Jones T et al (2013) Differential central pathology and cognitive impairment in pre-diabetic and diabetic mice. Psychoneuroendocrinology 38(11):2462-2475. doi:10.1016/j.psyneuen.2013.05.010

42. Li XL, Aou S, Oomura Y, Hori N, Fukunaga K, Hori T (2002) Impairment of long-term potentiation and spatial memory in leptin receptor-deficient rodents. Neuroscience 113(3):607-615

43. Huang S, Wang Y, Gan X, Fang D, Zhong C, Wu L, Hu G, Sosunov AA et al (2014) Drp1-Mediated Mitochondrial Abnormalities Link to Synaptic Injury in Diabetes Model. Diabetes. doi:10.2337/db140758

44. Dinel AL, Andre C, Aubert A, Ferreira G, Laye S, Castanon N (2011) Cognitive and emotional alterations are related to hippocampal inflammation in a mouse model of metabolic syndrome. PLoS One 6(9), e24325. doi:10.1371/journal.pone.0024325

45. Kim B, Backus C, Oh S, Hayes JM, Feldman EL (2009) Increased tau phosphorylation and cleavage in mouse models of type 1 and type 2 diabetes. Endocrinology 150(12):5294-5301. doi:10.1210/ en.2009-0695
46. Vincent AM, Perrone L, Sullivan KA, Backus C, Sastry AM, Lastoskie C, Feldman EL (2007) Receptor for advanced glycation end products activation injures primary sensory neurons via oxidative stress. Endocrinology 148(2):548-558. doi:10.1210/en.20060073

47. Kim B, Sullivan KA, Backus C, Feldman EL (2011) Cortical neurons develop insulin resistance and blunted Akt signaling: a potential mechanism contributing to enhanced ischemic injury in diabetes. Antioxidants Redox Signal 14(10):1829-1839. doi:10.1089/ ars.2010.3816

48. Antunes F, Cadenas E, Brunk UT (2001) Apoptosis induced by exposure to a low steady-state concentration of $\mathrm{H} 2 \mathrm{O} 2$ is a consequence of lysosomal rupture. Biochem J 356(Pt 2):549-555

49. Li W, Yuan XM, Olsson AG, Brunk UT (1998) Uptake of oxidized LDL by macrophages results in partial lysosomal enzyme inactivation and relocation. Arterioscler Thromb Vasc Biol 18(2):177-184

50. Cataldo AM, Hamilton DJ, Nixon RA (1994) Lysosomal abnormalities in degenerating neurons link neuronal compromise to senile plaque development in Alzheimer disease. Brain Res 640(1-2):6880

51. Cataldo AM, Paskevich PA, Kominami E, Nixon RA (1991) Lysosomal hydrolases of different classes are abnormally distributed in brains of patients with Alzheimer disease. Proc Natl Acad Sci U S A 88(24):10998-11002

52. Diedrich JF, Minnigan H, Carp RI, Whitaker JN, Race R, Frey W 2nd, Haase AT (1991) Neuropathological changes in scrapie and Alzheimer's disease are associated with increased expression of apolipoprotein E and cathepsin D in astrocytes. J Virol 65(9): 4759-4768

53. Schwagerl AL, Mohan PS, Cataldo AM, Vonsattel JP, Kowall NW, Nixon RA (1995) Elevated levels of the endosomal-lysosomal proteinase cathepsin D in cerebrospinal fluid in Alzheimer disease. J Neurochem 64(1):443-446

54. Tanabe A, Matsuda M, Fukuhara A, Miyata Y, Komuro R, Shimomura I, Tojo H (2009) Obesity causes a shift in metabolic flow of gangliosides in adipose tissues. Biochem Biophys Res Commun 379(2):547-552. doi:10.1016/j.bbrc.2008.12.086

55. Nakamura Y, Takeda M, Suzuki H, Hattori H, Tada K, Hariguchi S, Hashimoto S, Nishimura T (1991) Abnormal distribution of cathepsins in the brain of patients with Alzheimer's disease. Neurosci Lett 130(2):195-198

56. Hamed EA, Zakary MM, Abdelal RM, Abdel Moneim EM (2011) Vasculopathy in type 2 diabetes mellitus: role of specific angiogenic modulators. J Physiol Biochem 67(3):339-349. doi:10.1007/ s13105-011-0080-8

57. Zaidi N, Maurer A, Nieke S, Kalbacher H (2008) Cathepsin D: a cellular roadmap. Biochem Biophys Res Commun 376(1):5-9. doi: 10.1016/j.bbrc.2008.08.099

58. Hwang JJ, Lee SJ, Kim TY, Cho JH, Koh JY (2008) Zinc and 4hydroxy-2-nonenal mediate lysosomal membrane permeabilization induced by $\mathrm{H} 2 \mathrm{O} 2$ in cultured hippocampal neurons. J Neurosci: Off J Soc Neurosci 28(12):3114-3122. doi:10.1523/JNEUROSCI. 0199-08.2008

59. Kagedal K, Johansson U, Ollinger K (2001) The lysosomal protease cathepsin D mediates apoptosis induced by oxidative stress. FASEB J: Off Publ Fed Am Soci Exp Biol 15(9):1592-1594

60. Moheimani F, Kim CH, Rahmanto AS, van Reyk DM, Davies MJ (2012) Inhibition of lysosomal function in macrophages incubated with elevated glucose concentrations: a potential contributory factor in diabetes-associated atherosclerosis. Atherosclerosis 223(1):144 151. doi:10.1016/j.atherosclerosis.2012.04.026 